Filozofska fakulteta,Univerza v Ljubljani

gemma.santiago@ff.uni-lj.si

Pregelj, Barbara (2014): Leo, leo: priročnik motiviranja branja za šolsko leto 2014/2015. Medvode: Malinc. ISBN 978-961-6886-10-9, mehka vezava, 44 strani, 10 EUR

\title{
PREGELJ, BARBARA: LEO, LEO: PRIROČNIK MOTIVIRANJA BRANJA ZA ŠOLSKO LETO 2014/2015
}

El presente manual se presenta como una útil herramienta con el que los tutores ayudarán a descubrir a sus alumnos la sensibilidad literaria de cultivar el placer de leer de forma lúdica y creativa.

El libro ofrece 8 propuestas de lectura acompañadas de estrategias de lectura creativas en torno al libro y a las palabras, que entrelazan la lectura con otras formas de expresión: la oralidad, la escritura, la imagen, la declamación, la plástica, etc. La mayoría de las estrategias siguen con fidelidad las estrategias de Montserrat Sartó (1984), aunque en otras muchas ocasiones las amplía o actualiza con gran acierto, siempre buscando acercamientos integrales hacia los libros seleccionados desde diferentes perspectivas. Todas y cada una de las propuestas del libro giran siempre en torno a los libros elegidos, cuya finalidad es la creación de situaciones creativas y comunicativas en la que la lectura y la comprensión lectora personal de cada uno de los niños sea el objetivo primordial para que la lectura obtenga todo su sentido. Se trata, por tanto, de un cambio de dirección con el trabajo de la lectura en el aula en el que el objetivo final no es tanto que sepan leer como que deseen leer, y esto el libro lo consigue a través de sus múltiples propuestas y estrategias.

La selección de cada uno de los libros de lectura responde no solo a un criterio estético o de calidad, sino que los 8 libros en su conjunto fomentan además de la motivación a la lectura y el desarrollo estético del niño, el desarrollo afectivo, intelectual y social del niño, puesto que las propuestas integradas en el libro plantean situaciones y actividades que ponen en contacto la lectura con la experiencia personal y vital del niño. Asimismo, las propuestas planteadas en el libro convierten al lector en un lector crítico capaz de interpretar los textos, un lector que va más allá de la mera descodificación de las palabras.

A través de todas las diferentes actividades propuestas que abordan los 8 libros, se busca asimismo:

- desarrollar la capacidad de escuchar, comprender y retener del niño,

- desarrollar su capacidad analítica, sintética y creativa, 
- conseguir otras formas de comunicación no estereotipada a través de la recreación, proyección e invención,

- evolucionar de una lectura pasiva a una lectura activa,

- utilizar la lectura como estímulo para superar los propios problemas del niño,

- ampliar su visión del mundo al ponerle en contacto con otras realidades y culturas desde una actitud de respeto y empatía.

Uno de los grandes logros de este libro es la excelente selección de los textos literarios que aúnan a escritores consagrados de la literatura en español (Juan Kruz Igerabide, Mariasun Landa, Isol, Care Santos, Patxi Zubizarreta) con reconocidos ilustradores (Mikel Valverde, Andrés Guerrero, Mojca Fo, Elena Odiozola y Emilio Urberuaga). Igualmente, las lecturas recomendadas se presentan en versiones bilingües español-eslovenas, lo que supone la gran aportación y originalidad del manual de Pregelj, puesto que la motivación a la lectura utiliza el español como un elemento de estimulación extra que pone en contacto al niño con otra realidad diferente a la realidad eslovena, familiarizándolo desde muy temprana edad con la existencia del otro, de lo extranjero, no desde el punto de vista de la diferencia sino desde la acertada perspectiva de los puntos de unión. Asimismo, muchas de las actividades planteadas, además de fomentar la lectura, ayudan también a acercarse a la lengua española desde otras perspectivas de aprendizaje más creativas (otro de los grandes aciertos es la creación a través de las diferentes propuestas del libro de girasoles o trenes de vocabulario donde el niño puede visualizar a través de las diferentes historias leídas todas las nuevas palabras aprendidas en español).

Cada una de las estrategias vienen siempre acompañadas de descripciones claras y sencillas que atienden a la descripción del grupo, los objetivos y el desarrollo de las diferentes actividades, los instrumentos necesarios para la realización de las actividades, el tiempo necesario, un apartado especial que nos informa de posibles complicaciones y cómo resolverlas, y un atractivo último apartado donde se plantean actividades extras bajo el sugerente título de «otros retos». Lo interesante de cada una de las estrategias es que se trabajan todos los sentidos del niño, siempre desde una sensibilidad artística y creativa, tanto individual como social.

A través de cada una de las estrategias trabajadas, no solo se sensibiliza y motiva al niño a la lectura, sino que también tiene su primer acercamiento al español, y sobre todo a través de la selección de los libros y de las diferentes estrategias utilizadas en clase, el libro de Pregelj ayuda al niño a enfrentarse de manera creativa a temas tan universales como son la tristeza, el miedo, el extrañamiento, lo diferente, el yo, la familia, etc. Y a través del libro el niño aprenderá a verbalizar mejor su mundo interior a través de los diferentes personajes de los libros. Todas estas lecturas convierten al niño en un ser con conciencia y emocionalmente despierto capaz de verbalizar el mundo en el que vive, y todo ello Pregelj lo consigue gracias a todas las actividades planteadas en el libro. 


\section{BIBLIOGRAFÍA}

SARTO, M. (1998). Animación a la lectura, nuevas estrategias. Madrid: SM.

MARINA, J.A. (1998). "Prólogo" en Animación a la lectura, nuevas estrategias. Madrid:

SM. 